\title{
Pengaruh Video Animasi terhadap Hasil Belajar Siswa Muatan Pembelajaran IPA Kelas IV di SD Negeri 08 Sungai Rumbai
}

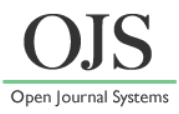

\author{
Sonia Yulia Friska *, Maulidya Tri Amanda, Ana Novitasari, Gingga Prananda \\ Prodi Pendidikan Guru Sekolah Dasar, Universitas Dharmas Indonesia, Sumatera Barat \\ *Email: soniayuliafriska@undhari.ac.id
}

DOI: https://doi.org/10.33369/pendipa.6.1.250-255

\begin{abstract}
The purpose of this study was to determine whether there was an effect on student learning outcomes who were taught using animated video learning media for class IV at SD Negeri 08 Sungai Rumbai for the Academic Year 2021/2022. The subjects in this study were students of class IV-2 SD Negeri 08 Sungai Rumbai, totaling 16 students. This type of quantitative research with experimental design in the form of pre-experimental design type one group pretest-posttest (before and after being treated by using animated videos). Data collection techniques in this study, which is done by using a test in the form of multiple choice questions. Based on the results of normality, it can be concluded that the significance obtained from the pretest data is $0.81<0.05$ and the significance obtained from the posttest data is $0.59<0.05$. The results of the hypothesis test from the paired samples test can be obtained a significant value of 0.000. The test results show a significant value $<0.05$, which is $0.000<0.05$. The results of the paired samples test show that $H_{0}$ was rejected and $\mathrm{Ha}$ was accepted in using animated video learning media on the content of science learning there is a significant effect on student learning outcomes before and after being given treatment in class IV SD Negeri 08 Sungai Rumbai.
\end{abstract}

Keywords: Animated videos, student learning outcomes, natural sciences.

\begin{abstract}
ABSTRAK
Tujuan penelitian ini untuk mengetahui apakah terdapat pengaruh hasil belajar siswa yang diajarkan menggunakan media pembelajaran video animasi kelas IV di SD Negeri 08 Sungai Rumbai Tahun Ajaran 2021/2022. Subjek dalam penelitian ini adalah siswa kelas IV-2 SD Negeri 08 Sungai Rumbai yang berjumlah 16 orang siswa. Jenis penelitian kuantitatif dengan design eksperimen dalam bentuk preexperimental design tipe one group pretest-posstest (sebelum dan sesudah diberi perlakuan dengan menggunakan video animasi). Teknik pengumpulan data dalam penelitian ini, yaitu dilakukan dengan menggunakan tes yang berupa soal pilihan ganda. Berdasarkan hasil normalitas maka dapat disimpulkan bahwa siginifikansi yang diperoleh dari data pretest yaitu $0,81<0,05$ dan signifikansi yang diperoleh dari data posttest yaitu $0,59<0,05$. Hasil uji hipotesis dari uji paired samples test dapat diperoleh nilai signifikan 0,000. Hasil pengujian terlihat nilai signifikan $<0,05$, yaitu $0,000<0,05$. Maka hasil uji paired samples test dapat disimpulkan bahwa $\mathrm{H}_{0}$ ditolak dan $\mathrm{Ha}$ diterima dalam menggunakan media pembelajaran video animasi pada muatan pembelaran IPA terdapat pengaruh yang signifikan terhadap hasil belajar siswa sebelum dan sesudah diberi perlakuan di kelas IV SD Negeri 08 Sungai Rumbai.
\end{abstract}

Kata kunci: Video Animasi, Hasil Belajar Siswa, Ilmu pengetahuan alam. 


\section{PENDAHULUAN}

Berdasarkan Undang-Undang Republik Indonesia Nomor 20 Tahun 2003 tentang Sistem Pendidikan Nasional pasal 1 mengatur bahwa pendidikan merupakan usaha sadar dan terencana untuk mewujudkan suasana belajar dan proses pembelajaran agar peserta didik secara aktif mengembangkan potensi dirinya untuk memiliki kekuatan spiritual keagamaan, pengendalian diri, kepribadian, kecerdasan, akhlak mulia, serta keterampilan yang diperlukan dirinya, masyarakat,bangsa dan negara. Setiap orang berhak mendapatkan pendidikan yang layak. Pendidikan dapat ditempuh melalui dua cara, yaitu pendidikan fomal dan pendidikan nonformal. Melalui pendidikan seseorang diharapkan dapat mengembangkan seluruh potensi di dalam dirinya agar menjadi seorang individu yang memiliki kecerdasan, keterampilan, dan kepribadian yang luhur.

Menurut Prananda dkk. (2021), pendidikan adalah proses peningkatan kualitas pengetahuan, sikap, dan perilaku manusia dan tidak hanya mengembangkan kecerdasan, tetapi juga meningkatkan nilai dan karakter moral siswa, serta menunjukkan kecerdasan dalam kehidupan sosial melalui penanaman. Undang-Undang Sisdiknas No. 20 Tahun 2003 Pasal 37 Ayat (1) yang menyebutkan muatan pembelajaran IPA sangat penting di kurikulum pendidikan dasar, dan pendidikan menengah. Ilmu

Menurut Friska dkk., (2020), Ilmu Pengetahuan Alam merupakan salah satu mata pelajaran yang pokok dalam kurikulum pendidikan di Indonesia, temasuk pada jenjang sekolah dasar. Menurut (Dewi dkk., 2017) Ilmu Pengetahuan Alam merupakan salah satu muatan pembelajaran yang diajarkan di SD menyatakan "IPA adalah ilmu pengetahuan yang mempelajari gejala-gejala melalui serangkaian proses yang dikenal dengan proses ilmiah yang dibangun atas dasar sikap ilmiah". (Hutauruk \& Simbolon, 2018) menyatakan bahwa IPA merupakan muatan pembelajaran yang sangat penting untuk dipelajari di tingkat SD, sebab membahas tentang peristiwa- peristiwa yang terjadi di alam dan dekat dengan kehidupan siswa tersebut.

Berdasarkan observasi peneliti di SD Negeri 08 Sungai Rumbai. Sebelum pandemi, sekolah menggunakan K-13. Pembelajarannya per-tema dan per-subtema, sekolah dilakukan dari hari senin-sabtu dari jam 07.00 WIB-12.00 WIB. Dari wawancara dengan siswa kelas IV tersebut guru kurang menggunakan media saat pembelajaran. Dan Sewaktu pembelajaran daring sekolah tetap memakai K-13, pembelajaran K-13 Per-tema dan Per-subtema selama 2 bulan (bulan juli-bulan Agustus). Di bulan September SD Negeri 08 Sungai Rumbai pembelajaran nya sudah tatap muka dengan syarat Guru dan siswa disekolah tidak ada yang Positif Covid-19 dan menjaga jarak serta mematuhi protocol kesehatan. Semasa pembelajaran tatap muka, sekolah menggunakan kurikulum khusus dari Pemerintah Dharmasraya, yang dimana kurikulum khusus, yaitu K-13 yang pembelajarannya Per-muatan pembelajaran. Pemerintah Dharmasraya juga menyediakan Bahan ajar yang berupa kaset pembelajaran berisi modul pembelajaran dan media pembelajaran sehingga guru lebih mudah untuk menerapkan kurikulum khusus tersebut kepada siswa, tetapi media yang di berikan oleh Pemerintah tidak mencangkup semua materi pembelajaran. Pada Semester II Pemerintah juga memberikan kaset pembelajaran yang berisi hanya modul saja. Hingga guru hanya menggunakan Modul yang diberikan oleh Pemerintah.

Berdasarkan hasil observasi di SD Negeri 08 Sungai Rumbai peneliti menemukan bahwa hasil belajar siswa pada muatan pembelajaran IPA masih rendah. Hal ini dapat dilihat dari hasil ujian harian siswa Kelas IV SDN 08 Sungai Rumbai yang dirangkum di dalam Tabel 1.

Tabel 1. Data hasil ujian harian siswa pada kelas IV-2 di SD Negeri 08 Sungai Rumbai.

\begin{tabular}{|c|c|c|}
\hline \multirow[b]{2}{*}{ Ketuntasan } & \multicolumn{2}{|c|}{ Kelas IV } \\
\hline & $\begin{array}{c}\text { A } \\
\text { (tidak } \\
\text { menggunakan } \\
\text { video animasi) }\end{array}$ & Data \\
\hline $\begin{array}{l}\text { Nilai siwa } \\
\text { di atas } \\
\text { KKM } 75\end{array}$ & 6 siswa & $37.5 \%$ \\
\hline $\begin{array}{l}\text { Nilai siswa } \\
\text { di bawvah } \\
\text { KKM } 75\end{array}$ & 10 siswa & $62.5 \%$ \\
\hline Jumlah & 16 Siswa & $100 \%$ \\
\hline
\end{tabular}

Sumber: Guru Kelas IV-2 di SD Negeri 08 Sungai Rumbai

Berdasarkan Tabel 1 dapat disimpulkan bahwa hasil belajar siswa masih rendah. Salah satu faktor penyebab rendahnya hasil belajar 
siswa pada kelas IV di SD Negeri 08 Sungai Rumbai, yakni media pembelajaran kurang maksimal yang digunakan oleh guru dan media pembelajaran yang diberikan tidak mencangkup semua materi hanya beberapa materi saja. Guru hanya menggunakan bahan ajar, yaitu: buku atau modul pembelajaran. Sehingga belum mampu meningkatkan hasil belajar siswa dalam pembelajaran serta siswa belum di bawa ke dalam kehidupan nyata sehingga siswa sulit untuk memahami pelajaran tersebut.

Berdasarkan permasalahan terhadap rendahnya hasil belajar siswa, sehingga perlu adanya suatu media yang efektif dapat menanggulangi permasalahan tersebut. Media pembelajaran yang digunakan hendaknya berpengaruh terhadap hasil belajar siswa. Guna mewujudkan hal tersebut guru dapat menggunakan media pembelajaran seperti: Video Animasi.

Menurut Ayuningsih, (2017) menyatakan media merupakan suatu alat penyalur materi yang telah dirancang oleh guru. Prananda dkk., 2020 menyatakan Media merupakan segala sesuatu yang digunakan sebagai perantara untuk menyampaikan materi pembelajaran di dalam sebuah proses belajar dan kata media merupakan bentuk jamak dari kata medium. (Rahmayanti \& Istianah, 2018) menyatakan bahwa media adalah sesuatu yang digunakan sebagai penyalur atau penghubung materi yang telah direncanakan guru untuk menyampaikan tujuan pembelajaran.

Menurut Ayuningsih, (2017) Media pembelajaran membuat pembelajaran lebih efektif dan efesien, media pembelajaran yang digunakan guru, yaitu media pembelajaran video animasi. Media pembelajaran video animasi adalah media yang berisi gambar-gambar serta audio. Menurut Jatmiko dkk., (2017) Media pembelajaran merupakan bagian dari sumber belajar dan sekaligus bagian integral teknologi pendidikan yang perlu dimanfaatkan dan didayagunakan untuk menunjang keefektifitas proses pembelajaran. Ilmi \& Tajuddin, 2021) menyatakan media pembelajaran merupakan peralatan yang berbentuk fisik yang didesain secara tersusun untuk menyampaikan informasi.

Prananda, Saputra, dkk., (2020) menyatakan bahwa hasil belajar merupakan umpan balik dalam proses pembelajaran yaitu tolak ukur yang digunakan untuk mengetahui apakah siswa memahami pembelajaran yang telah dipelajarinya. maka pelaksanaan IPA akan berjalan dengan baik, selain itu guru harus dapat mengambangkan kemampuan siswa secara efektif, menarik siswa secara aktif, dan melatih siswa untuk meningkatkan kemampuan berpikir dan mengungkapkan pendapat. Baswan, (2014) menyatakan hasil belajar merupakan kemampuan yang dicapai siswa dari proses belajar yang dapat diketahui dari pencapaian saat melakukan serangkaian tes hasil belajar. Afandi et al., (2013) menyatakan bahwa hasil belajar akan tampak pada beberapa aspek antara lain: pengetahuan, pengertian, kebiasaan, keterampilan, apresiasi, emosional, hubungan sosial, jasmani, etis atau budi pekerti, dan sikap.

\section{METODE PENELITIAN}

Peneliti menggunakan jenis penelitian kuantitatif dengan metode penelitiannya yaitu ekperimen. Peneliti menggunakan desain ekperimennya yaitu pre-experimental designs bentuk one-grouppretest-posttest design. Tempat penelitian di kelas IV-2 SD Negeri 08 Sungai Rumbai, waktu penelitian pada tanggal 22 Juni s/d 2 Juli 2021. Populasi dan sampel pada kelas IV-2 berjumlah 16 siswa. Pengambilan sampel dalam penelitian ini menggunakan sampling kouta. Teknik pengumpulan data menggunakan soal tes pilihan ganda dan soal mencocokkan pada. Pengembangan instrumen yang berupa uji validtas, uji reliabilitas, tingkat kesukaran, dan daya beda. Teknik analisis data menggunakan perhitungan statistika dengan uji normalitas dan uji hipotesis pada SPSS 20.

\section{HASIL DAN PEMBAHASAN Hasil}

Pada penelitian ini terdapat 16 siswa pada kelas IV di SD Negeri 08 Sungai Rumbai yang telah ditetapkan menjadi sampel penelitian. Sebelum dilakukan treatment (perlakuan) kepada siswa, siswa di berikan soal pretest terlebih dahulu. Selanjutnya siswa diberikan treatment (perlakukan) dengan menggunakan media pembelajaran video animasi. Setelah diberikan treatment, terakhir siswa diberikan soal posttest untuk mengetahui hasil belajar siswa. Setelah 
diperoleh data pretest dan posttest siswa kelas IV SD Negeri 08 Sungai Rumbai, selanjutnya data disajikan menurut nilai tertinggi (Xmaks), nilai terendah (Xmin), dan nilai rata-rata siswa. Adapun data hasil pretest dan posttest dapat disajikan pada tabel dibawah ini:

Tabel 2. Data Hasil Pretest dan Posttest Siswa

\begin{tabular}{|l|l|l|l|}
\hline No & Deskripsi Data & Pretest & Posttest \\
\hline 1 & Jumlah Siswa & 16 & 16 \\
\hline 2 & Jumlah Nilai & 1000 & 1271 \\
\hline 3 & Rata-rata & 62,5 & 79,4 \\
\hline 4 & Xmaks & 80 & 97 \\
\hline 5 & Xmin & 31 & 60 \\
\hline
\end{tabular}

Berdasarkan analisis pada pretest dan posttest siwa diatas, dapat dijelaskan bahwa nilai rata-rata pretest siswa yaitu 62,5 dan nilai ratarata posttest siswa yaitu 79,4 . Berdasarkan nilai pretest dan posttest tersebut dapat dilihat bahwa nilai pretest lebih rendah dari nilai posttest. Untuk dapat melihat dengan jelas perbandingannya nilai pretest dan posttest siswa maka peneliti menyajikan dalam bentuk diagram. Berikut ini diagram perbandingan nilai rata-rata pretest dan posttest siswa kelas IV-2.

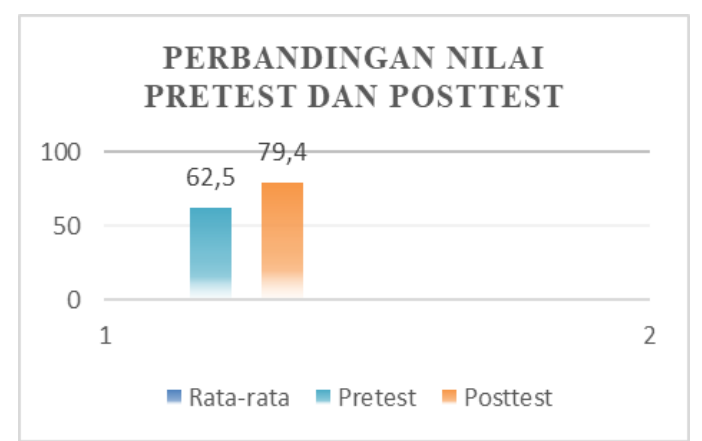

Gambar 1. Perbandingan Nilai Pretest dan Posttest Kelas IV-2

Gambar diatas menyajikan perbandingan nilai rata-rata pretest dan posttest siswa kelas IV2. Nilai pretest adalah 62,5 sedangkan nilai posttest adalah 79,4 . Jadi selisih antara nilai pretest dan posttest yaitu sebesar 16,9. Dari selisih tersebut dapat dilihat bahwa Perbandingan nilainya meningkat dari nilai rata-rata pretest ke nilai rata-rata posttest. Artinya nilai siswa meningkat setelah diberikan treatment video animasi.

Sebelum sebelum diberi perlakuan, siswa diberikan materi pembelajaran IPA, serta peneliti melakukan observasi terhadap hasil belajar siswa sebelum diberi perlakuan, kemudian diberikan perlakuan menggunakan media pembelajaran video animasi serta peneliti melakukan obsevasi terhadap hasil belajar siswa setelah diberikan perlakuan. Berikut ini hasil dari obsevasi hasil belajar siswa sebekum diberikan perlakuan dan sesudah diberi perlakuan, disajikan pada gambar berikut.

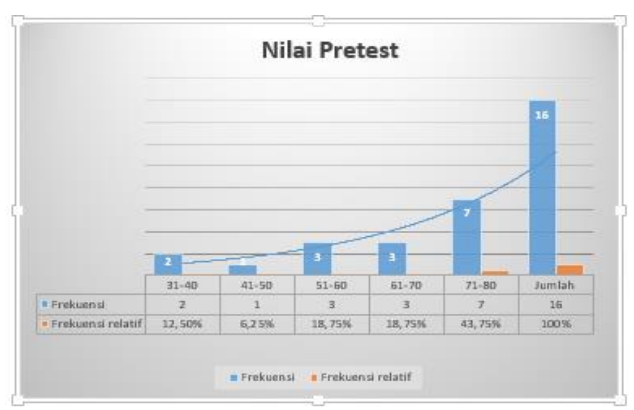

Gambar 2. Nilai Pretest

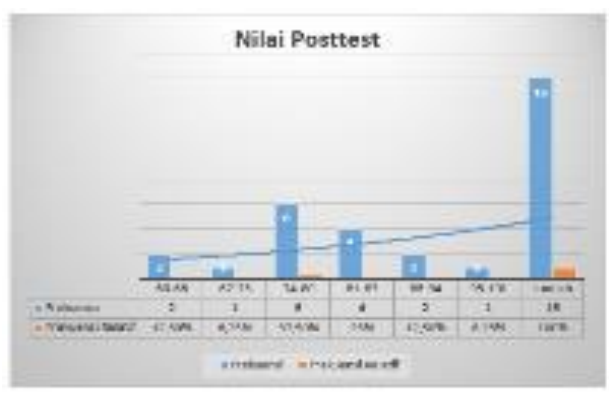

Gambar 3. Nilai Posttest

Setelah mendapatkan data hasil pretest dan posstest, dapat diperoleh data skor pretest dan data skor posstest pada siswa kelas IV-2, observasi tersebut untuk melihat pengaruh hasil belajar siswa dalam muatan pembelajaran IPA kelas IV di SD Negeri 08 Sungai Rumbai sebelum dan sesudah perlakuan.

Sebelum melakukan uji hipotesis, dapat dilakukan yaitu, uji normalitas kemudian uji hipotesis. Data diuji untuk mengetahui apakah data yang didapat hasilnya normal atau tidak. Setelah data berdistribusi normal kemudian uji hipotesis. Uji normalitas dan uji hipotesis dilakukan dengan bantuan SPSS 20, 
menggunakan tes Kolmogorof Smirnov, dengan kriterianya adalah jika signifikansi hasil lebih besar dari 0,05 artinya berdistribusi normal. Sedangkan jika signifikansi hasil lebih kecil dari 0,05 artinya tidak berdistribusi normal. Data yang diuji normalitasnya yaitu pretest dan posttest. Berikut ini tabel uji normalitas data pretest dan posttest kelas IV SD Negeri 08 Sungai Rumbai.

Tabel 1. Hasil Uji Normalitas Pretest dan Tests of Normality Posttest

\begin{tabular}{|l|l|l|l|}
\hline \multirow{2}{*}{} & \multicolumn{3}{|l|}{ Kolmogoro v-Smirnov ${ }^{\text {a }}$} \\
\cline { 2 - 4 } & Statistic & df & Sig. \\
\hline PreTest &, 202 & 16 &, 081 \\
PostTest &, 210 & 16 &, 059 \\
\hline
\end{tabular}

Berdasarkan tabel diatas, dapat dilihat bahwa signifikan yang didapat pada data pretest yaitu $0,81>0,05$ dan signifikansi yang didapat pada data posttest yaitu $0,59>0,05$. Artinya data pretest dan posttest siswa kelas IV SD Negeri 08 Sungai Rumbai adalah berdistribusi normal.

Pengujian hipotesis dilakukan untuk mengetahui apakah hipotesis yang diajukan diterima atau ditolak. Setalah data pretest dan posttest hasil belajar IPA berdistribusi normal, maka setelah itu dilakukan uji hipotesis dengan menggunakan SPSS 20. Peneliti melakukan uji paired samples t-test. Uji paired samples t-test bertujuan untuk mengetahui apakah ada pengaruh atau tidak terhadap model pembelajaran yang digunakan dalam proses pembelajaran pada kelas IV-2. Berikut ini adalah tabel uji paired samples ttest.

Paired Samples Test

Tabel 2. Hasil Uji Paired Samples T Test

\begin{tabular}{|c|c|c|c|c|c|c|c|c|}
\hline & \multicolumn{5}{|c|}{ Paired Differences } & \multirow[t]{3}{*}{$t$} & \multirow[t]{3}{*}{ df } & \multirow[t]{3}{*}{ Sig. (2-tailed) } \\
\hline & \multirow[t]{2}{*}{\begin{tabular}{|l|} 
Mean \\
\end{tabular}} & \multirow[t]{2}{*}{\begin{tabular}{|l|} 
Std. \\
Deriation
\end{tabular}} & \multirow{2}{*}{$\begin{array}{l}\text { Std. } \\
\text { Enor } \\
\text { Mean }\end{array}$} & \multicolumn{2}{|c|}{$\begin{array}{l}95 \% \text { Confidence Interval } \\
\text { of the Difference }\end{array}$} & & & \\
\hline & & & & Lower & Upper & & & \\
\hline \begin{tabular}{|ll} 
& PreTest - \\
Pair 1 & PostTest \\
&
\end{tabular} & $-16,938$ & 8,652 & 2,163 & $-21,548$ & $-12,327$ & $-7,830$ & 15 &, 000 \\
\hline
\end{tabular}

Berdasarkan tabel diatas, dapat diperoleh signifikansi dari uji paired samples $t$ test yaitu $0,000<0,05$ artinya $\mathrm{H}_{0}$ ditolak dan $\mathrm{H}_{\mathrm{a}}$ diterima. Maka dapat disimpulkan bahwa terdapat pengaruh media pembelajaran video animasi terhadap hasil belajar siswa muatan pembelajaran IPA pada kelas IV-2.

\section{Pembahasan}

Pada hari pertama penelitian yang dilakukan pada kelas IV-1 yaitu validasi soal, jumlah soal yang di validasi adalah 25 soal pilihan ganda dan 6 soal mencocokkan. Setelah soal di jawab oleh siswa di periksa dan di uji reliabilitas, uji validitas tingkat kesukaran, dan daya beda dengan menggunakan Ms. Excel. Maka hasil yang di dapat setelah di uji reliabilitas, validitas, tingkat kesukaran, dan daya beda adalah 20 soal pilihan ganda dan 5 soal mencocokkan.

Pada hari berikutnya Pemberian soal pretest kepada siswa sebelum pemberian treatment (perlakuan). Sebagaimana yang terlihat pada hasil pretest hanya 3 orang siswa yang mencapai kriteria ketuntasan minimal (KKM) 75, dimana rata-rata kelas hanya 62,5. Hasil tersebut dapat dinyatakan masih rendah karena belum mencapai KKM. Selain itu, hasil tersebut menunjukkan adanya masalah pada proses pembelajaran sehingga berdampak pada hasil belajar siswa yang belum maksimal. Selanjutnya peneliti melaksanakan treatment (perlakuan) yang dilaksanakan sebanyak 5 pertemuan.

Pelaksanaan treatment dilakukan sesuai RPP yang telah dibuat. Setelah pemberikan treatment (perlakuan), selanjutnya peneliti memberikan soal posttest kepada siswa. Hasil posttest meningkat dari hasil pretest, yang dimana nilai menacapai diatas KKM. Selain itu, semua siswa mencapai ketuntasan, dimana hasil yang diperoleh sangat baik, nilai tertinggi pada pretest mencapai angka 80, nilai tertinggi pada posttest mencapai angka 97, nilai terendah pada pretest mencapai angka 31, dan nilai terendah pada posttest mencapai angka 60 .

Usai dilaksanakan penelitian pada kelas IV-2 diperoleh data pretest dan posttest. Setelah itu data pretest dan posttest di uji normalitas dan uji hipotesisnya. Hasil uji normalitas data pretest dan posttest memperoleh signifikan data pretest yaitu, $0,81>0,05$ dan signifikan yang diperoleh dari data 
posttest yaitu, 0,59>0,05 yang artinya data pretest dan posttest berdistribusi normal.

Setelah data berdistribusi normal, selanjutnya dilakukan uji hipotesis dengan menggunakan uji paired samples t test. Hasil uji paired samples $t$ test yang diperoleh yaitu $0,000<0,05$ artinya $\mathrm{H}_{\mathrm{a}}$ diterima dan $\mathrm{H}_{0}$ ditolak, artinya terdapat pengaruh media pembelajaran video animasi terhadap hasil belajar siswa muatan pembelajaran IPA Kelas IV di SD Negeri 08 Sungai Rumbai.

\section{KESIMPULAN}

Setelah dilakukan penelitian terhadap pengaruh media pembelajaran video animasi terhadap hasil belajar siswa muatan pembelajaran IPA kelas IV SD Negeri 08 Sungai Rumbai, selanjutnya dilakukan pengolahan data yaitu uji normalitas dan uji hipotesis menggunakan uji paired samples $t$ test. Hasil uji paired samples $t$ test memperoleh signifikansi yaitu $0,000<0,05$ artinya $\mathrm{H}_{0}$ ditolak dan $\mathrm{H}_{\mathrm{a}}$ diterima. Maka dapat ditarik kesimpulan bahwa terdapat pengaruh media pembelajaran video animasi terhadap hasil belajar siswa muatan pembelajaran IPA kelas IV di SD Negeri 08 Sungai Rumbai.

\section{DAFTAR PUSTAKA}

Afandi, M., Chamalah, E., \& Wardani, oktarina puspita. (2013). Model Dan Metode Pembelajaran Disekolah (cetakan 1). UNISSULA PRESS.

Ayuningsih, K. (2017). Pengaruh Video Animasi Terhadap Hasil Belajar Kognitif Pada Mata Pelajaran IPS Materi Menghargai Jasa Pahlawan di Kelas V SDN Sidokumpul Sidoarjo. Journal of Information and Computer Technology Education, 1(April), $1-7$.

http://ojs.umsida.ac.id/index.php/jicte/articl e/view/1129/762

Baswan. (2014). Meningkatkan Hasil Belajar Siswa Pada Mata Pelajaran PKN Pada Materi Susunan Pemerintahan Daerah Melalui Metode Bermain Peran dikelas IV SD di Siboang. Kreatif Tadulako Online, 3 no.(1), 258-275.

Dewi, N. M. J., Putra, D. K. N. S., \& Ganing, N. (2017). Pengaruh Model Pembelajaran Problem Based Learning Berbantuan Media Audio Visual Animasi Terhadap Hasil
Belajar Ipa. E-Journal PGSD Universitas Pendidikan Ganesha, 5(2), 1.

Friska, S. Y., Pahmi, S., \& Prananda, G. (2020). Pengaruh Model NHT Terhadap Hasil Belajar IPA. Jurnal Iaktan Alumni PGSD UNARS, 9(1), 332-342.

Hutauruk, P., \& Simbolon, R. (2018). Meningkatkan Hasil Belajar Siswa Dengan Alat Peraga Pada Mata Pelajaran IPA Kelas IV SDN Nomor 14 Simbolon Purba. School Education Journal, 8(2), 112.

Ilmi, N., \& Tajuddin, R. (2021). Pengaruh Media Video Animasi Terhadap Kemampuan Menulis Karangan Narasi Siswa Sekolah Dasar. Journal of Social Sciences and Humanities, 1(1), 38-44. https://ojs.unm.ac.id/societies/article/view/ 19418/10264

Jatmiko, P. D., Wijayantin, A., \& Susilaningsih, S. (2017). Pengaruh Pemanfaatan Video Pembelajaran Terhadap Hasil Belajar Ipa Kelas Iv Sekolah Dasar. Edcomtech Jurnal Kajian Teknologi Pendidikan, 1(2), 153156.

Prananda, G., Friska, S. Y., \& Susilawati, W. O. (2021). Pengaruh Media Konkret Terhadap Hasil Belajar Materi Operasi Hitung Campuran Bilangan Bulat Siswa Kelas IV Sekolah Dasar. Jurnal Edukasi Matematika Dan Sains, 9(1), 1-10. https://doi.org/10.25273/jems.v9i1.8421

Prananda, G., Saputra, R., \& Ricky, Z. (2020). Meningkatkan Hasil Belajar Menggunakan Media Lagu Anak Dalam Pembelajaran IPA Sekolah Dasar. Jurnal Ika, 8(2), 304-314.

Prananda, G., Wardana, A., \& Yuliadarmianti. (2020). Pengembangan Media Video Pembelajaran Tema 6 Subtema 2 Untuk Siswa Kelas SD Negeri 17 Pasar Masurai 1. Jurnal Dharma PGSD, 1(1).

Rahmayanti, L., \& Istianah, F. (2018). Pengaruh Penggunaan Media Video Animasi Terhadap Hasil Belajar Siswa Kelas V SDN Se-Gugus Sukodono Sidoarjo. Jurnal PGSD, 6(4), 429-439. 